\title{
ISOMETRIC KNEE TORQUE, QUADRICEPS-HAMSTRINGS RATIO, AND JUMPING PARAMETERS IN BRAZILIAN SOCCER PLAYERS OF DIFFERENT AGE CATEGORIES
}

original paper

() Wroclaw University of Health and Sport Sciences

DOI: https://doi.org/10.5114/hm.2022.107972

\author{
ISABELLA FERREIRA $^{1 \oplus}{ }^{\oplus}$, JEFFERSON DOS SANTOS ${ }^{1 \oplus}$, MATHEUS SOUZA ${ }^{1 \oplus}$, \\ ANDERSON TEIXEIRA $^{2 \oplus}{ }^{\oplus}$, AUGUSTO BARBOSA ${ }^{3}{ }^{\circledR}$, FÁBIO NAKAMURA $^{4}{ }^{\oplus}$, \\ ALEXANDRE BARBOSA ${ }^{1}$ (1) \\ ${ }^{1}$ Musculoskeletal Research Group, Department of Physical Therapy, Federal University of Juiz de Fora, \\ Governador Valadares, Brazil \\ ${ }^{2}$ Research Group for Development of Football and Futsal / Physical Effort Laboratory, Sports Centre, Federal University \\ of Santa Catarina, Florianópolis, Brazil \\ ${ }^{3}$ Meazure Sport Sciences, São Paulo, Brazil \\ ${ }^{4}$ Associate Graduate Program in Physical Education, Federal University of Paraíba, João Pessoa, Brazil
}

\begin{abstract}
Purpose. This study assessed the isometric torque, hamstring-to-quadriceps ratio, and jump performance among three age groups of soccer players.

Methods. 67 male players were divided by chronological age into the under-17 (U17: $n=29$ ), under-20 (U20: $n=22$ ), and above-20-year (PRO: $n=16$ ) groups. They performed countermovement (CMJ) and squat (SJ) jumps. Also, maximal isometric contractions during knee flexion and extension for right (R-TOR) and left limb (L-TOR) torque were assessed. Hamstrings-quadriceps (H:Q) and CMJ:SJ ratios were determined.

Results. Compared with U17 and U20, PRO showed higher CMJ $(\Delta=20 \%$ and $14 \%$; both $p<0.01)$ and SJ ( $\Delta=19 \%$ and $13 \% ; p<0.01$ and $p=0.02$, respectively), and higher absolute R-TOR and L-TOR during knee extension ( $\Delta=40 \%$ and $58 \%$; both $p<0.01$ ). PRO exhibited higher absolute L-TOR and R-TOR during knee flexion than U17 ( $\Delta=22 \%$ and 26\%; $p=0.04$ and $p<0.01$, respectively). Between-group differences were not detected in normalized torque, except for knee extension $\mathrm{R}-\mathrm{TOR}(\mathrm{PRO}>\mathrm{U17} ; p=0.04)$. Greater differences for quadriceps absolute torque (effect size: 1.37-1.46) were observed in the hamstrings (effect size: $0.30-0.92$ ) between PRO and U17. No differences were found for any H:Q torque ratio, but moderate effect sizes (0.71-0.75) were verified between PRO and the other groups. No differences were found for CMJ:SJ ratio.

Conclusions. PRO players are more powerful than U17 and U20. Differences in strength level between PRO and U17/U20 are muscle-dependent. The larger strength development of quadriceps over hamstrings can result in lower isometric H:Q torque ratio for PRO.
\end{abstract}

Key words: muscle strength, power, sports, athletic performance

\section{Introduction}

The soccer game involves unpredictable and unconventional actions with a significant amount of backward running, sideway movements, skipping, and shuffling [1, 2]. High-intensity runs are also frequent and decisive, and are generally combined with acceleration and deceleration, changes of directions, jumps, heading, kicking, and dribbling [1, 2]. The evolution of both technical and tactical performance in soccer has been accompanied by a progressive increase in game speed [3], thus requiring neuromuscular qualities to optimize the mechanical actions of the players [4]. Studies have reported that competitive or simulated matches impair neuromuscular performance assessed through isometric or concentric/eccentric muscle

Correspondence address: Alexandre C. Barbosa, Musculoskeletal Research Group, Department of Physical Therapy, Federal University of Juiz de Fora, R. Leonardo Cristino, 3400 - São Geraldo, Gov. Valadares, Minas Gerais, Brazil, CEP 35012000, e-mail: alexwbarbosa@hotmail.com, https://orcid.org/0000-0001-7862-1737

Received: September 29, 2020

Accepted for publication: February 8, 2021

Citation: Ferreira I, dos Santos J, Souza M, Teixeira A, Barbosa A, Nakamura F, Barbosa A. Isometric knee torque, quadricepshamstrings ratio, and jumping parameters in Brazilian soccer players of different age categories. Hum Mov. 2022;23(3):81-91; doi: https://doi.org/10.5114/hm.2022.107972. 
actions and vertical jumps in both professional and youth soccer players [5-7], highlighting its high neuromuscular demands.

It has been demonstrated that a variety of physical capacities, mainly aerobic performance and repeatedsprint ability, improve gradually throughout the youth player's specialization process [8-10]. The available information regarding power-speed-related abilities is less abundant though [11]. Surprisingly, recent studies have shown no significant age- or training-level-related differences in crucial neuromuscular performance attributes, such as 20-m-sprint and change-of-direction speeds [9, 12]. These controversial findings indicate that further comparative studies regarding the development of physical components among different competitive age groups are needed.

Muscular strength and vertical jump performance are expected to increase with age owing to interaction between growth- and maturity-related changes with the training process in adolescent soccer players [13-15]. The age-related development of muscular strength and jump performance includes neuromuscular, biomechanical, and structural changes. For instance, there are increases in muscle size, voluntary activation level, musculotendinous stiffness, moment arm length, muscle architecture properties (e.g., pennation angle and fascicle length), and body size measures (e.g., body mass). These changes combined may result in greater muscular strength levels and jump performance [16]. Increasing muscular strength levels are especially recommended to prepare the players to sustain the high work rates throughout training and matches [4], as well as to mitigate their injury risk [17]. It is also important to proportionally increase the knee extensor and flexor ability to produce force so that an imbalance in the hamstring/quadriceps (H:Q) torque ratio can be avoided, and knee joint stability is thereby maintained. Interestingly, cross-sectional studies have found a dissimilar pattern of the H:Q torque ratio across age and maturity groups in youth soccer and basketball players, with a linear trend for isokinetic knee extensors strength values and a quadratic curvilinear pattern for knee flexors muscles, reaching a plateau approximately two years after the maximum growth rate in height (i.e., peak height velocity) [13, 18]. It is then suggested that older and early maturing players during the talent development process may be more susceptible to hamstring muscle injuries (e.g., tear or ruptures) [13, 18].

Neuromuscular qualities are commonly evaluated by isokinetic dynamometers, which provide parameters of isometric and dynamic muscle functions $[13,17]$.
However, more affordable and less time-consuming tools have emerged to safely and reliably assess the lower-limb strength and power for quadriceps and hamstrings under field conditions, such as load cells and inertial sensors [19-21]. These devices can be more accessible to teams competing at a sub-elite level and provide useful information about how youth players have developed and the state of readiness of adult players to face the next soccer match and training loads.

While most of the studies are focused on assessing both elite youth and professional players training in the most prestigious and traditional soccer clubs and academies [12, 22, 23], researchers and practitioners should also pay attention to the athletic development of the players from clubs with limited financial resources as the training load management (e.g., training content, quality, and quantity) can be completely distinct and less elaborated [24]. Moreover, sub-elite players tend to be less physically developed than elite ones [22, 23]. On the other hand, within a more practical perspective, some of these players are regularly promoted to elite clubs owing to their refined technical skills either during early ages (11-17 years) or closer to the highest competitive level (18-23 years). Therefore, further studies describing muscle power and strength profile of sub-elite soccer players are warranted. Such information is essential to identify the physical qualities that should be optimized at the sub-elite level with the aim to diminish the performance gap between players of different competitive levels.

This study aimed to evaluate and compare neuromuscular qualities (isometric torque, hamstring-toquadriceps ratio, and jumping performances) between two age groups (U17, U20) and adult sub-elite soccer players. In addition, the relationship between H:Q torque ratio and knee extensors isometric torque was also examined for the total sample. We hypothesized that the older male soccer players would present higher muscle strength and power, and lower H:Q torque ratio values than the younger ones.

\section{Material and methods}

\section{Study design}

This cross-sectional comparative study examined possible differences in strength and power qualities of three official age-group categories of soccer players (U17, U20, and PRO) from two Brazilian soccer clubs. During the first month of the 2019-2020 pre-season, the athletes performed the following tests: vertical jumps and lower limb isometric torque. The results were then 
compared across the age-group categories. The test sessions were carried out at the same time of day (afternoon) and under the same experimental conditions. Team training intensity and volume were reduced the day before testing, and the players were instructed to consume their usual diet on the days before testing. No food intake was allowed in the 2-3 hours before testing. Only one player was tested at a time, and they instructed and verbally encouraged to put in their maximal effort during the assessments.

\section{Participants}

A total of 67 male soccer players (Table 1) took part in this study. A one-tailed post-hoc power analysis was performed with the consideration of the minimum effect size (ES) of 0.30, an alpha level of 0.05, and the sample of 67 participants (G*POWER ${ }^{\mathrm{TM}}$ software, version 3.1.5, Franz Faul, Universität Kiel, Germany). The returned power was 0.809 . The athletes were grouped in accordance with their chronological age $[11,25]$ into 3 categories: U17 $(n=29), \mathrm{U} 20(n=22)$, and above-20-year (PRO, $n=16$ ). The objectives of the study were explained to the participants and to their legal guardians, and they were all notified of the benefits and potential risks involved.

\section{Vertical jumping ability}

The vertical jumping ability was assessed by the squat (SJ) (standard error of measurement: $0.84 \mathrm{~cm}$; coefficient of variation [CV]: $1.50 \%$; intraclass correlation coefficient [ICC]: 0.98 ; 95\% confidence interval [95\% CI]: 0.96-0.99; $\mathrm{F}=102.70 ; p<0.01)[26]$ and countermovement (CMJ) (standard error of measurement: $1.29 \mathrm{~cm} ; \mathrm{CV}=1.30 \%$; ICC $=0.99 ; 95 \% \mathrm{CI}$ : 0.99-1.00; $\mathrm{F}=355.37 ; p<0.01)$ jumps $[9,12,19,27]$.
In SJ, a static position with a $90^{\circ}$ knee flexion angle was kept for $2 \mathrm{~s}$ before a jump attempt without any preparatory movement. In CMJ, the athletes performed a downward movement followed by a complete lower limbs extension. They freely determined the amplitude of the countermovement to avoid changes in the jumping coordination pattern [28]. All jumps were executed with the hands on the hips. Two attempts of each jump were performed with 15 -s intervals between the trials $[9,12,25,29]$. The mean result of the trials was retained for analysis.

A G-Sensor (BTS ${ }^{\mathrm{TM}}$ Bioengineering Corp., Quincy, MA, USA) was positioned on the lower back with the centre of the device corresponding to the S1-S2 vertebrae, in accordance with the manufacturer's user guide, and measured the jump height and flight time for each attempt. The device consists of a triaxial accelerometer (16 bit/axis; $8 \mathrm{~g}$ ), a triaxial magnetometer (13 bit; $1200 \mu \mathrm{T}$ ), a triaxial gyroscope (16 bit/axis; $250 \%$ s), and a global positioning system receiver [30]. Additionally, the CMJ:SJ ratio was calculated to assess the efficiency of the players in the utilization of the stretch-shortening cycle. The data were extracted by the G-Studio software (BTS ${ }^{\mathrm{TM}}$ Bioengineering Corp., Quincy, MA, USA) and the jump heights were determined by the flight time using the following equation:

$$
\text { (gravity } \left.\cdot \text { flight time }{ }^{2}\right) / 8
$$

The sensor validity was compared with an optoelectric system [20], which resulted in a very strong correlation between both devices $(r=0.91 ; p<0.01$; bias: $1.80 \pm 1.80 \mathrm{~cm}$ ).

\section{Isometric force}

The knee flexion-extension isometric force was assessed with a load cell (model MNCS-M; Bode Tech-

Table 1. Participants' characteristics

\begin{tabular}{|c|c|c|c|c|}
\hline Outcome & U17 & U20 & $\mathrm{PRO}$ & Differences \\
\hline$n$ & 29 & 22 & 16 & - \\
\hline Age (years) & $16 \pm 0.9$ & $19 \pm 0.7$ & $24 \pm 3$ & $\mathrm{PRO}>\mathrm{U} 20>\mathrm{U} 17$ \\
\hline Weight (kg) & $63 \pm 9$ & $66 \pm 9$ & $74 \pm 8$ & $\mathrm{PRO}>\mathrm{U} 20 ; \mathrm{PRO}>\mathrm{U} 17$ \\
\hline Height (cm) & $175 \pm 9$ & $175 \pm 7$ & $175 \pm 6$ & NS \\
\hline $\operatorname{BMI}\left(\mathrm{kg} / \mathrm{m}^{2}\right)$ & $21 \pm 2$ & $21 \pm 2$ & $24 \pm 2$ & $\mathrm{PRO}>\mathrm{U} 20 ; \mathrm{PRO}>\mathrm{U} 17$ \\
\hline R-thigh perimeter $(\mathrm{cm})^{\mathrm{a}}$ & $50 \pm 5$ & $50 \pm 6$ & $50 \pm 4$ & NS \\
\hline L-thigh perimeter $(\mathrm{cm})^{\mathrm{a}}$ & $50 \pm 5$ & $50 \pm 5$ & $49 \pm 5$ & NS \\
\hline R-leg height $(\mathrm{cm})$ & $48 \pm 4$ & $47 \pm 6$ & $40 \pm 3$ & $\mathrm{PRO}<\mathrm{U} 20 ; \mathrm{PRO}<\mathrm{U} 17$ \\
\hline L-leg height (cm) & $47 \pm 4$ & $46 \pm 6$ & $40 \pm 3$ & $\mathrm{PRO}<\mathrm{U} 20 ; \mathrm{PRO}<\mathrm{U} 17$ \\
\hline
\end{tabular}

U17 - under-17 group, U20 - under-20 group, PRO - professional group, BMI - body mass index, R - right, L - left, NS - non-significant

${ }^{a}$ The perimeter was assessed at the midpoint of the thigh length. Significant differences were assumed at $p<0.05$. 


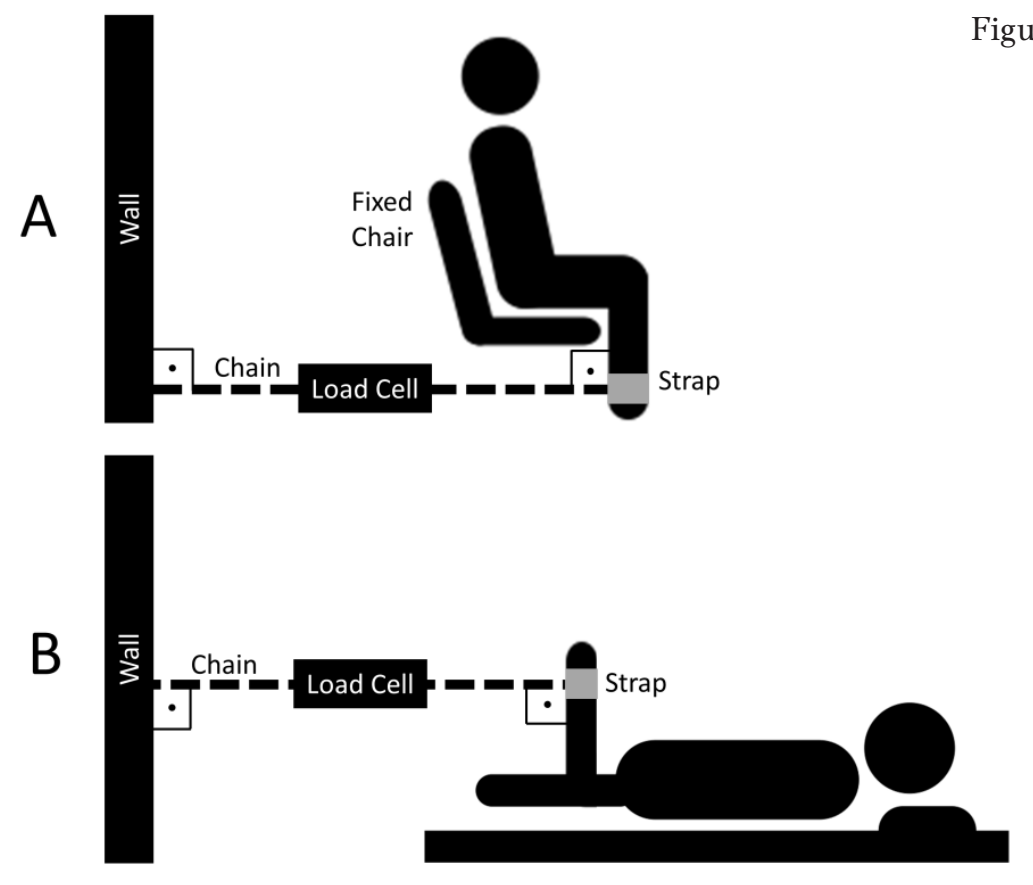

Figure 1. Setup for the assessment of flexion (A) and extension (B) forces

nical Services, Denver, CO, USA; maximum tensioncompression $=200 \mathrm{kgf}$; precision $=0.1 \mathrm{kgf}$; 5 -digit display; refresh rate of the load cell display $=30 \mathrm{~Hz}$ ) in both lower limbs (right [R] and left [L]). Each leg was tested 3 times (10-s contraction and 1-minute rest between the trials) by using the load cell fixed to the wall with a chain and the volunteer's ankle with a strap (Figure 1). The average of the 2 best results was retained for analysis. Knee extension and flexion were assessed with the volunteer seated on a chair with the feet resting on the floor, knees and hips flexed at $90^{\circ}$ (Figure 1). The load cell cable was positioned perpendicularly to the centre of the knee joint. The direct measurement of the leg length was performed by using a tape measure (accuracy: $1 \mathrm{~mm}$ ) from the head of the fibula to the lateral malleolus. Goniometric measurements ensured the same positions in all assessments. The same researcher gave a standardized verbal command ('prepare,' 'force') for all athletes. The load cell display was video-recorded at $60 \mathrm{~Hz}$ and peak force was obtained through a posterior video frame-by-frame analysis. The torque (TOR) was calculated as the product between the peak force and the moment arm, corresponding to the individual leg length (in meters). Torque measures are expressed in absolute $(\mathrm{N} \cdot \mathrm{m})$ and relative $(\mathrm{N} \cdot \mathrm{m} / \mathrm{kg})$ values. Muscle imbalances of each limb were assessed through a ratio (H:Q) between knee flexors and extensors torque. The validity of the load cell had been evaluated in a previous study [31]. We also verified the reliability for the torque in the right (standard error of measurement: $31.7 \mathrm{~N} \cdot \mathrm{m} ; \mathrm{CV}=9.10 \%$;
ICC $=0.92 ; 95 \%$ CI: 0.79-0.97; F = 23.82; $p<0.01$ ) and left extension (standard error of measurement: $29.1 \mathrm{~N} \cdot \mathrm{m} ; \mathrm{CV}=7.00 \%$; ICC = 0.96; 95\% CI: 0.89-0.98; $\mathrm{F}=45.29 ; p<0.01$ ), and right (standard error of measurement: $22.80 \mathrm{~N} \cdot \mathrm{m} ; \mathrm{CV}=7.70 \%$;CC $=0.81 ; 95 \%$ CI: $0.55-0.93 ; \mathrm{F}=9.47 ; p<0.01$ ) and left flexion (standard error of measurement: $23.60 \mathrm{~N} \cdot \mathrm{m} ; \mathrm{CV}=$ 6.20\%; ICC $=0.85 ; 95 \%$ CI: 0.64-0.94; F = 12.38; $p<$ $0.01)$. The leg preference of the players was not monitored.

\section{Statistical analyses}

Data were presented as mean and standard deviation. The Shapiro-Wilk test checked the data distribution. Data distribution normality was accepted, and the multivariate analysis of variance (MANOVA) general linear model assessed between-group individual differences; to extend the analysis, we took into account multiple continuous dependent variables, bundling them together into a weighted linear combination or composite variable (Pillai's trace). Holm's post-hoc test was performed for pairwise comparisons. The standardized differences for the comparisons of all variables were analysed by using Cohen's $d$ ES. The magnitude of $E S$ was interpreted with the following thresholds: $<0.2$, trivial; 0.2-0.6, small; 0.6-1.2, moderate; 1.2-2.0, large; 2.0-4.0, very large; > 4.0, nearly perfect [26]. Pearson's coefficient $(r)$ assessed the correlation among the $\mathrm{H}: \mathrm{Q}$ ratios and TOR values, and was interpreted as: $<0.1$, trivial; 0.1-0.3, small; 0.3-0.5, moderate; 0.5-0.7, 
large; $0.7-0.9$, very large; $>0.9$, nearly perfect [26]. The significance was set at $p<0.05$. The analyses were performed with the Jamovi software (version 1.2; The JAMOVI Project, 2020; retrieved from: https://www. jamovi.org).

\section{Ethical approval}

The research related to human use has complied with all the relevant national regulations and institutional policies, has followed the tenets of the Declaration of Helsinki, and has been approved by the Federal University of Juiz de Fora ethics committee for human investigation (reference number: 25180919.2.0000. 5147).

\section{Informed consent}

Informed consent has been obtained from all individuals included in this study.

\section{Results}

The groups did not perform co-interventions and the participants reported no adverse effects during the assessments. All variables presented between-group differences in a composite factor (Pillai's $\mathrm{F}_{[22,110]}=2.17$; $p<0.01$ ), whereas univariate differences were detected for $\mathrm{CMJ}(\mathrm{F}=8.68 ; p<0.01)$ and $\mathrm{SJ}(\mathrm{F}=7.79 ; p<0.01)$ height. Knee extension (R: $\mathrm{F}=10.98, p<0.01 ; \mathrm{L}: \mathrm{F}=$ 8.50, $p<0.01)$ and flexion (R: $\mathrm{F}=5.32, p<0.01 ; \mathrm{L}: \mathrm{F}=$ $8.50, p<0.01)$ also exhibited torque differences.
Table 2 summarizes the descriptive data. Compared with both U17 and U20 (respectively), PRO showed greater CMJ height $(p<0.01, E S=1.24$ [large]; $p=$ $0.01, E S=0.95$ [moderate]), CMJ flight time $(p<0.01$, $E S=1.24$ [large]; $p=0.03, E S=0.98$ [moderate]), $\mathrm{SJ}$ height $(p<0.01, E S=1.16$ [moderate]; $p=0.02, E S=$ 0.88 [moderate]), SJ flight time $(p<0.01, E S=1.46$ [large]; $p=0.03, E S=1$ [moderate]), R-TOR $(p<0.01$, $E S=1.46$ [large]; $p<0.01, E S=1.22$ [large]), and L-TOR $(p<0.01, E S=1.37$ [large]; $p<0.01, E S=1.03$ [moderate]) during knee isometric extension. Compared with U17, PRO also presented higher R-TOR $(p<0.01$, $E S=0.92$ [moderate] $)$ and L-TOR $(p=0.04, E S=0.30$ [small]) during flexion. The groups did not differ when torque measures were normalized by body mass, with the exception of knee extensor R-TOR, which remained significantly lower in U17 compared with PRO ( $p=$ $0.04, E S=0.83$ [moderate]).

No significant differences were found for right- $(\mathrm{F}=$ $2.69, p=0.07)$ or left-limb $(\mathrm{F}=2.57, p=0.08) \mathrm{H}$ :Q ratio. However, owing to marginal values, pairwise $E S$ values were calculated. Moderate ES were determined between PRO and both U17 ( $E S=0.72$ for R-H:Q, $E S=$ 0.71 for L-H:Q) and U20 ( $E S=0.74$ for R-H:Q, $E S=$ 0.75 for L-H:Q). Only trivial $E S$ values were observed between U17 and U20 ( $E S=0.08$ for R-H:Q, $E S=0.03$ for L-H:Q). No significant differences were found for the CMJ:SJ ratio $(\mathrm{F}=0.06, p=0.93)$ (Figure 2$)$.

The R-H:Q was moderate and negatively correlated with R-TOR extension $(r=-0.70, p<0.01)$; it also

Table 2. Descriptive statistics (mean \pm standard deviation) for vertical jumping performance and knee extension and flexion torque for U17, U20, and professional soccer players, with pairwise comparisons derived from MANOVA and effect size values

\begin{tabular}{|c|c|c|c|c|c|c|}
\hline \multirow{3}{*}{ Outcomes } & & \multirow{2}{*}{\multicolumn{3}{|c|}{ Age groups }} & \multirow{2}{*}{\multicolumn{2}{|c|}{$\begin{array}{c}\text { Pairwise comparisons } \\
p \text { [effect size] }\end{array}$}} \\
\hline & & & & & & \\
\hline & & U17 & U20 & PRO & $\mathrm{PRO}>\mathrm{U} 17$ & $\mathrm{PRO}>\mathrm{U} 20$ \\
\hline $\mathrm{CMJ}$ & Height $(\mathrm{cm})$ & $29.3 \pm 4.7$ & $31 \pm 4.1$ & $35.3 \pm 4.9$ & 0.001 [1.24] & 0.010 [0.95] \\
\hline SJ & Height (cm) & $28.9 \pm 4.7$ & $30.5 \pm 4$ & $34.4 \pm 4.8$ & $0.001[1.16]$ & $0.020[0.88]$ \\
\hline \multirow{4}{*}{ Knee extension } & R-TOR (N · m) & $1004 \pm 432$ & $1117 \pm 388$ & $1584 \pm 375$ & $0.001[1.46]$ & 0.002 [1.22] \\
\hline & R-TOR $(\mathrm{N} \cdot \mathrm{m} / \mathrm{kg})$ & $16.2 \pm 7.0$ & $17.4 \pm 6.6$ & $21.4 \pm 4.9$ & 0.037 [0.83] & NS \\
\hline & L-TOR $(\mathrm{N} \cdot \mathrm{m})$ & $996 \pm 427$ & $1100 \pm 471$ & $1535 \pm 358$ & $0.001[1.37]$ & $0.006[1.03]$ \\
\hline & L-TOR $(\mathrm{N} \cdot \mathrm{m} / \mathrm{kg})$ & $16.0 \pm 6.8$ & $17.1 \pm 7.9$ & $20.8 \pm 4.5$ & NS & NS \\
\hline \multirow{4}{*}{ Knee flexion } & R-TOR $(\mathrm{N} \cdot \mathrm{m})$ & $480 \pm 123$ & $563 \pm 126$ & $604 \pm 145$ & $0.001[0.92]$ & NS \\
\hline & R-TOR $(\mathrm{N} \cdot \mathrm{m} / \mathrm{kg})$ & $7.7 \pm 1.9$ & $8.6 \pm 1.9$ & $8.2 \pm 1.8$ & NS & NS \\
\hline & L-TOR $(\mathrm{N} \cdot \mathrm{m})$ & $506 \pm 137$ & $573 \pm 150$ & $619 \pm 149$ & $0.040[0.30]$ & NS \\
\hline & L-TOR $(\mathrm{N} \cdot \mathrm{m} / \mathrm{kg})$ & $8.1 \pm 2.1$ & $8.8 \pm 2.6$ & $8.4 \pm 2.0$ & NS & NS \\
\hline
\end{tabular}

U17 - under-17 group, U20 - under-20 group, PRO - professional group, CMJ - countermovement jump,

SJ - squat jump, height - jump height, R - right, L - left, TOR - torque, NS - non-significant 


\section{HUMAN MOVEMENT}

I. Ferreira et al., Comparison of age categories in soccer
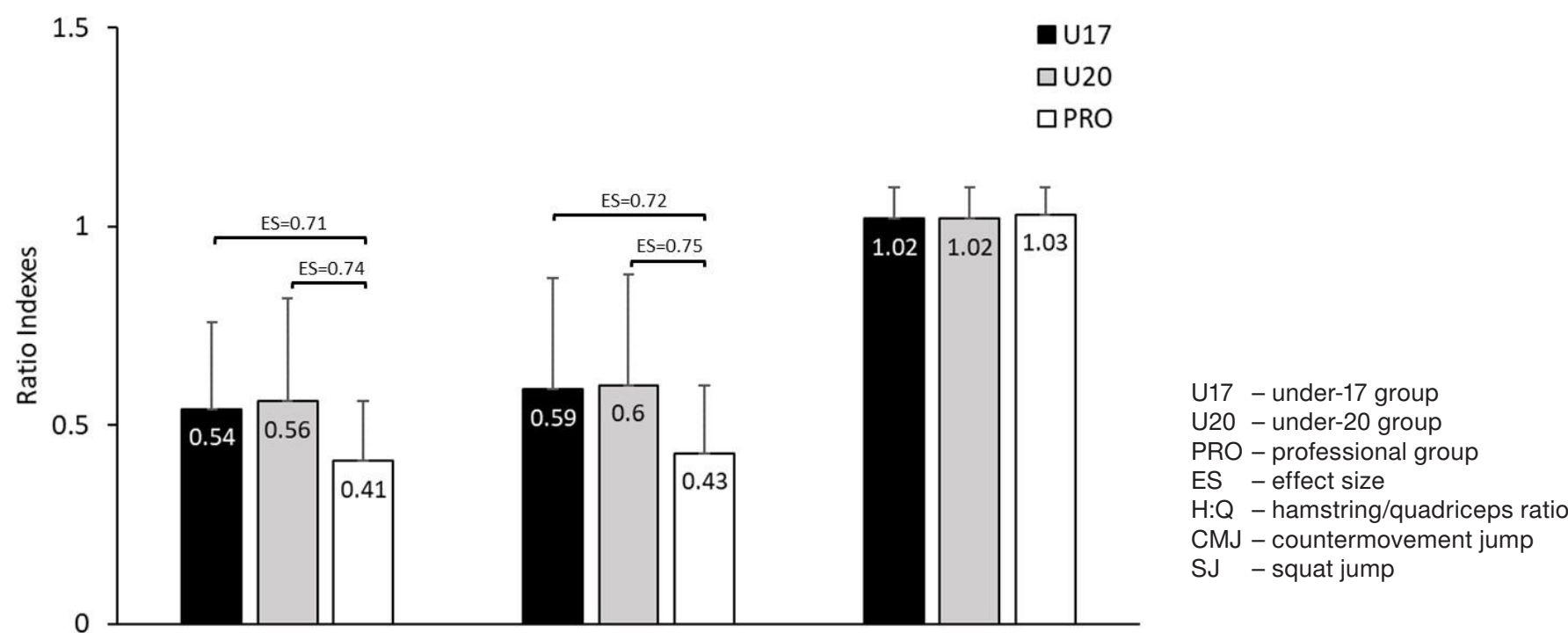

H:Q-Right H:Q-Left

CMJ:SJ

Figure 2. Ratio indexes

$\mathbf{A}$

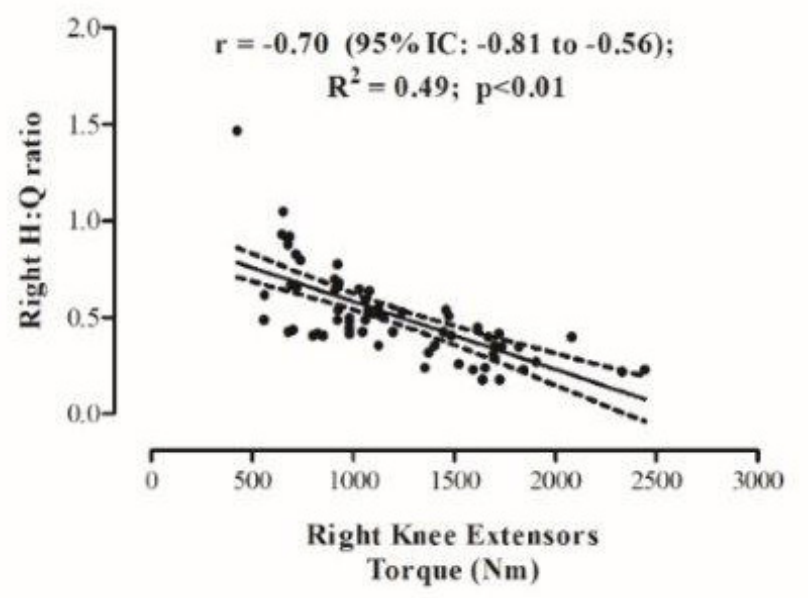

C

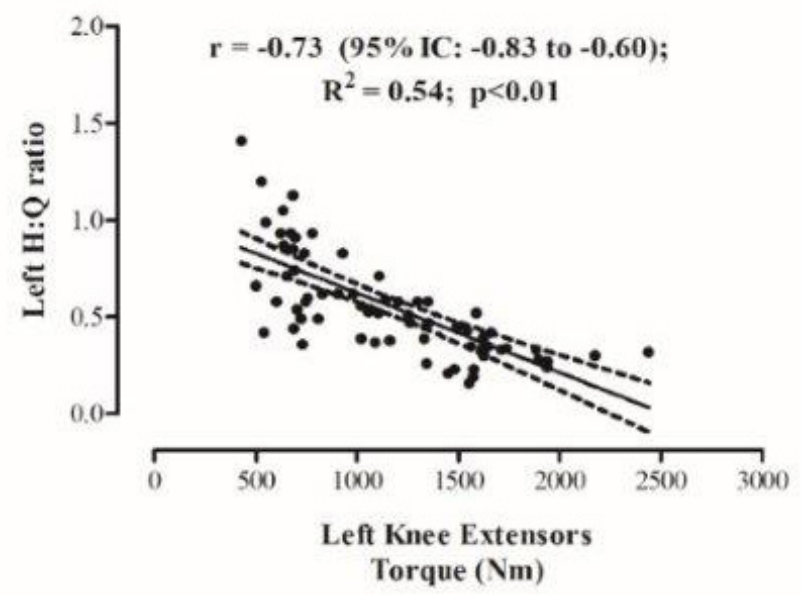

B

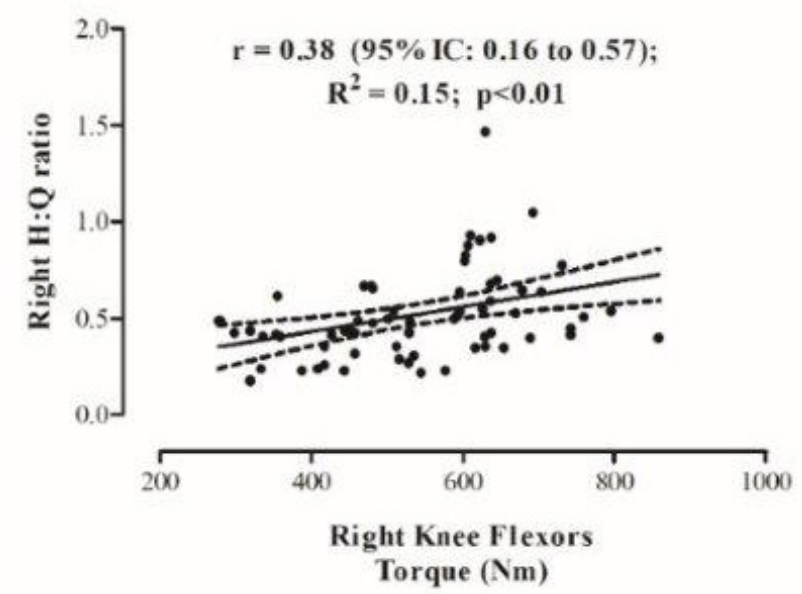

D

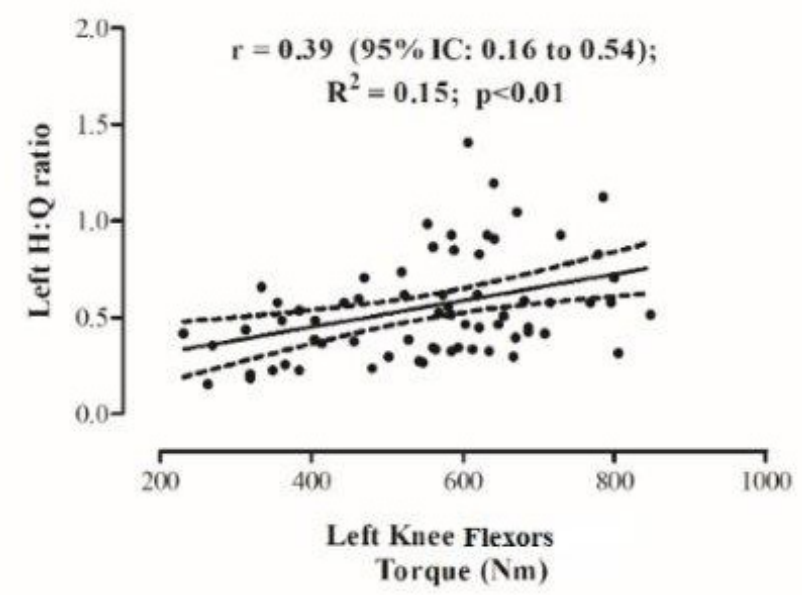

$\mathrm{H}: \mathrm{Q}$ - hamstring/quadriceps ratio

Figure 3. Relationships of the knee extensors and flexors isometric torque with right (panels A and B) and left (panels C and D) H:Q ratio $(n=67)$ 
showed a small positive correlation with R-TOR flexion $(r=0.38, p<0.01)$. The L-H:Q exhibited a large negative and a small positive correlation with L-TOR extension $(r=-0.73, p<0.01)$ and L-TOR flexion $(r=$ $0.39, p<0.01)$, respectively. The correlations are detailed in Figure 3.

\section{Discussion}

This study examined differences in vertical jump and isometric knee extension and flexion torques across three age categories (U17, U20, and PRO) of male soccer players. Our findings revealed consistent largeto-moderate differences in PRO over U17 and U20 players in $\mathrm{CMJ}$ and $\mathrm{SJ}$, as well as in isometric knee extension and flexion torques, whereas U17 and U20 players did not differ from each other. Furthermore, age-related differences between PRO and U17/U20 players for the isometric knee extension (large-to-moderate $E S$ ) were larger than those observed for the knee flexion torque (moderate-to-small $E S$ ).

Strength and conditioning coaches and sports scientists may benefit from understanding jumping performance changes from early adolescence to adulthood [9, 11, 12, 32], and the majority of prior research has consistently shown increases in jumping performance as players progress towards the senior category [11, 32]. However, cross-sectional studies indicated that vertical jumps (CMJ or SJ) did not differ between U17 and U20 elite players [9, 12, 33], suggesting slower improvements from U17 onward, or even a plateau. Similarly, CMJ and SJ were not different between U17 and U20 herein. Although CMJ $(29-31 \mathrm{~cm})$ and SJ $(29-30 \mathrm{~cm})$ of our athletes were lower than those in agematched top-level ones (CMJ: 35-44 cm; SJ: 35-38 cm) $[9,11,12,32-34]$, the development pattern of these indicators during the late adolescence (16-20 years) may be similar regardless of the competitive level. The lack of differences among these categories (i.e., 16-20 years) may be firstly related to a similar training stimulus to develop the lower-limb power. Second, the increased technical-tactical content during these age periods could minimize the increments in fat-free mass $[12,35]$, which has been identified as a predictor of CMJ performance in young players [11]. Third, there is a tendency to homogenize the groups in terms of anthropometry and physical characteristics, that is, prioritize recruiting early maturing players, who are stronger, more powerful, and faster than their teammates classified as delayed in biological maturation [36]. This last assumption must be viewed with caution, since no biological maturity indicator is available in our sample. Future studies may investigate whether the greater retention of early maturing players can mitigate age-related physical differences. Thus, all of these factors combined may partly explain the lack of differences between the U17 and U20 age groups in jumping performance.

The PRO players also presented greater $\mathrm{CMJ}(\Delta=$ $14-20 \%)$ and SJ $(\Delta=13-19 \%)$ than the U17 and U20. Although these differences are in line with prior studies among elite players [9, 27,33], other authors have reported similar vertical jumping performance in juniors (U20 and U17) and professionals (i.e., PRO) competing in the main world's soccer leagues (e.g., Brazilian and Spanish) [12, 34]. These data could suggest the inefficiency of the training methods in developing the adequate strength and power levels due to the typically congested calendar in professional soccer. On the other hand, jumping at the same level as their older and more experienced teammates could indicate that promising U20 players may partially meet the professional game requirements. Importantly, smaller differences are expected as players get closer to the highest competitive level [11].

Another aspect of practical relevance is the similarities between CMJ and SJ heights verified in all categories. The CMJ:SJ ratio has been proposed as an indicator of eccentric utilization during CMJ [37]. The lower CMJ:SJ ratio herein (1.02-1.03) compared with other studies (1.09-1.14) [37,38] indicates the inefficiency to utilize the stretch-shortening cycle. Strength and conditioning coaches should then search for effective power/strength training approaches (e.g., eccentric and plyometric training) to enhance the eccentric utilization during stretch-shortening cycle movements, especially with players at lower competitive level [39].

The long-term training in team sports may lead to muscular sport-specific development from childhood to adulthood [13, 18]. A progression of strength capacities across categories (i.e., with more time of soccer practice) is then expected, as previously noticed $[9,40]$. For instance, Kobal et al. [9] tested first division players and verified that the maximum dynamic strength (one-repetition maximum) in the squat exercise was considerably greater in PRO than in U17 and U20. In soccer, the actions performed during the games seem to have a greater effect on knee extension torque [13]. Herein, the isometric torque results for knee extension revealed the superiority of PRO over U17 and U20. More specifically, we demonstrated torque progressions (based on the means) of 11\% from U17 to U20, and $40 \%$ from U20 to PRO, despite a shorter lever arm in 
PRO. As changes in knee extensors strength levels may be associated with changes in functional tests, such as vertical jump and sprinting performance [9, 38, 41], it is conceivable that the differences from U17 and U20 to PRO may have induced lower vertical jump values. The knee flexor torque differed by $15 \%$ and $8 \%$ from U17 to U20 and from U20 to PRO, respectively. The hamstring muscles are important to decelerate and limit the forward motion of the leg after the kick, as well as to stabilize the knee joint [42], and their torque can differentiate players from different competitive levels (i.e., elite athletes present higher knee extensor torque than sub-elite and amateur ones) [42]. Although performance in soccer is not determined exclusively by measurable variables [42], strength capacities play an important role in physical, tactical, and technical tasks within the game and in injury prevention.

The variations in muscle torque between young and adult players can be attributed to differences in body size and composition, such as height, body mass, fat-free mass, and lower limb lean soft tissue [13, 17]. In this study, between-group differences were not detected when the relative torque was compared, except for the knee extensor R-TOR, which was higher in PRO than in U-17. This indicates that the variations in muscle torque among U-17, U-20, and PRO athletes are related to changes in body mass that occur during the growth or specialization process. Other factors, involving neural, biomechanical, and morphological components, may also have contributed to the greater ability to produce foce of the older players: tendon stiffness, muscle size, pennation angle, fascicle length [16]. However, the influence of these other determining factors is outside the scope of this study.

The assessment of the muscle imbalances throught the H:Q torque ratio has been used [17] to mitigate the occurrences of noncontact muscle injuries during the season. Through this information, the technical and medical staffs can improve their decision-making process, verify the individuals' muscle balance in accordance with the established references, and then individualize the training and treatment programs. The PRO isometric H:Q torque ratios (0.41 and 0.43) were similar to those found in an earlier study (0.45) with Danish elite soccer players [43], but comparatively lower than the 0.52 and 0.51 values reported by Greco et al. [44] and Thorlund et al. [5], respectively. Herein, PRO players exhibited lower values than the reference of 0.60 , commonly used for H:Q torque ratio in isokinetic testing [17], which possibly implies a greater injury risk [5]. For U17 and U20, the isometric $\mathrm{H}$ :Q torque ratios ( 0.54 and 0.60 , respectively) were slightly above the aforementioned values [5, 43, 44], but lower than those observed in novice soccer players (0.92-0.75) [45]. We acknowledge, though, that normative values of isometric H:Q torque ratio are lacking, and comparisons between studies should be performed with caution.

A distinct development pattern of the knee extension (linear) and flexion (curvilinear) torques throughout the adolescence period has been suggested $[13,18$, 45], but its influences on $\mathrm{H}: \mathrm{Q}$ torque ratio remains controversial. While Peek et al. [45] observed that the isometric H:Q torque ratio decreased from 0.91 to 0.60 between 8- and 15 year-old players, Duarte et al. [40] and Kellis et al. [14] reported that the effect of age on the dynamic and isometric H:Q torque ratio was negligible in soccer players aged 10 and 18 years. Herein, the isometric H:Q torque ratio did not differ between the U17 and U20 categories. Combined with previous results $[14,40,45]$, these data suggest that the isometric $H: Q$ ratio can decrease up to the age of 15 years and then reach a plateau as a consequence of the smaller changes that occur in the knee extension and flexion torque in the late adolescence period [40]. However, compared with U17 and U20, PRO athletes presented lower values of $\mathrm{H}: \mathrm{Q}$ torque ratio. Although non-significant (R: $p=0.07$; L: $p=0.08$ ), the moderate $E S$ values (ES: -0.71 to -0.75 ) may indicate differences of practical relevance. In agreement with a prior study [46], our results showed an inverse correlation between the isometric $\mathrm{H}: \mathrm{Q}$ torque ratio and knee extensor torque in both legs (R: $r=-0.70, p<0.01 ; \mathrm{L}: r=-0.73, p<0.01$ ), indicating the association between lower isometric $\mathrm{H}: \mathrm{Q}$ torque ratio and greater isometric knee extensor torque in PRO. In contrast to our findings, Gür et al. [47] revealed a higher functional H:Q torque ratio (eccentric $\mathrm{H} /$ concentric $\mathrm{Q}$ ) in professionals than in 18-yearold elite soccer players. Then, it is suggested that the decrease of the H:Q torque ratio in the sub-elite professional players is related to their lower hamstring strength. In accordance with this assumption, Commeti et al. [42] showed that amateur players had weaker hamstrings compared with professional players. These results have important implications for performance and injury prevention as decreased hamstring strength is recognized as a modifiable intrinsic injury risk factor [48]. The above observations indicate that the effects of age on the dynamic or isometric H:Q torque ratio may be evident when comparing adults and adolescents, but not among players in the late adolescence period. Further studies are necessary to broaden the body of information on this topic.

This study assessed important physical and injuryprevention indicators in different age-group categories 
of sub-elite soccer players by applying low-cost and more accessible technologies. These evaluations allowed to identify age-related differences between PRO and junior players and may provide useful information for technical and medical staffs. The assessment of neuromuscular function by using a G-Sensor or load cell may be an important addition to the testing battery for soccer academies since it can establish baseline jump performance and muscle strength values, provide information about the player's neuromuscular readiness state, detect strength asymmetries and low isometric $\mathrm{H}: \mathrm{Q}$ torque ratio, and also monitor longitudinal changes after injury.

The present study is not without limitations. Because of the cross-sectional design, the interpretation of our data is limited and generalization to other soccer samples of different competitive levels may not apply. Second, the normative values for isometric H:Q ratio have not been established yet and, therefore, the use of a conventional H:Q torque ratio of 0.60 based on isokinetic dynamometry should be interpreted with caution.

\section{Conclusions}

The PRO group presented higher vertical jumps and greater extensor and flexor torques than the younger U17 and U20 categories. These differences were smaller between PRO and U20. In addition, bigger differences for the torque results of quadriceps compared with hamstring muscles were observed among PRO than among younger players, which resulted in moderately lower isometric H:Q torque ratio values for PRO.

\section{Acknowledgements}

The present work was partially funded by the Coordenação de Aperfeiçoamento de Pessoal de Nível Superior, Brazil (Finance Code 001) and by the Fundação de Amparo à Pesquisa do Estado de Minas Gerais.

\section{Disclosure statement}

No author has any financial interest or received any financial benefit from this research.

\section{Conflict of interest}

The authors state no conflict of interest.

\section{References}

1. Bloomfield J, Polman R, O’Donoghue P. Deceleration movements performed during FA Premier League soccer matches. J Sports Sci Med. 2007;6(Suppl. 10):6.

2. Castagna C, D’Ottavio S, Abt G. Activity profile of young soccer players during actual match play. J Strength
Cond Res. 2003;17(4):775-780; doi: 10.1519/15334287(2003)017<0775:apoysp>2.0.co;2.

3. Barnes C, Archer DT, Hogg B, Bush M, Bradley PS. The evolution of physical and technical performance parameters in the English Premier League. Int J Sports Med. 2014;35(13):1095-1100; doi: 10.1055/s-00341375695.

4. Wisløff U, Castagna C, Helgerud J, Jones R, Hoff J. Strong correlation of maximal squat strength with sprint performance and vertical jump height in elite soccer players. Br J Sports Med. 2004;38(3):285-288; doi: 10.1136/bjsm.2002.002071.

5. Thorlund JB, Aagaard P, Madsen K. Rapid muscle force capacity changes after soccer match play. Int J Sports Med. 2009;30(4):273-278; doi: 10.1055/s-0028-110 4587.

6. Rampinini E, Bosio A, Ferraresi I, Petruolo A, Morelli A, Sassi A. Match-related fatigue in soccer players. Med Sci Sports Exerc. 2011;43(11):2161-2170; doi: 10.1249/ MSS.0b013e31821e9c5c.

7. Oliver J, Armstrong N, Williams C. Changes in jump performance and muscle activity following soccer-specific exercise. J Sports Sci. 2008;26(2):141-148; doi: 10.1080/02640410701352018.

8. Mujika I, Spencer M, Santisteban J, Goiriena JJ, Bishop D. Age-related differences in repeated-sprint ability in highly trained youth football players. J Sports Sci. 2009;27(14):1581-1590; doi: 10.1080/026404109033 50281.

9. Kobal R, Loturco I, Gil S, Cal Abad CC, Cuniyochi R, Barroso R, et al. Comparison of physical performance among Brazilian elite soccer players of different agecategories. J Sports Med Phys Fitness. 2016;56(4):376382 .

10. Valente-dos-Santos J, Coelho-e-Silva MJ, Martins RA, Figueiredo AJ, Cyrino ES, Sherar LB, et al. Modelling developmental changes in repeated-sprint ability by chronological and skeletal ages in young soccer players. Int J Sports Med. 2012;33(10):773-780; doi: 10.1055/ s-0032-1308996.

11. Deprez D, Valente-Dos-Santos J, Coelho-e-Silva MJ, Lenoir M, Philippaerts R, Vaeyens R. Longitudinal development of explosive leg power from childhood to adulthood in soccer players. Int J Sports Med. 2015;36(8): 672-679; doi: 10.1055/s-0034-1398577.

12. Loturco I, Jeffreys I, Cal Abad CC, Kobal R, Zanetti V, Pereira LA, et al. Change-of-direction, speed and jump performance in soccer players: a comparison across different age-categories. J Sports Sci. 2020;38(11-12): 1279-1285; doi: 10.1080/02640414.2019.1574276.

13. Forbes H, Bullers A, Lovell A, McNaughton LR, Polman RC, Siegler JC. Relative torque profiles of elite male youth footballers: effects of age and pubertal development. Int J Sports Med. 2009;30(8):592-597; doi: 10.1055/s-0029-1202817.

14. Kellis S, Gerodimos V, Kellis E, Manou V. Bilateral isokinetic concentric and eccentric strength profiles of 
the knee extensors and flexors in young soccer players. Isokinet Exerc Sci. 2001;9(1):31-39; doi: 10.3233/ ies-2001-0061.

15. Williams CA, Oliver JL, Faulkner J. Seasonal monitoring of sprint and jump performance in a soccer youth academy. Int J Sports Physiol Perform. 2011;6(2):264275; doi: 10.1123/ijspp.6.2.264.

16. Radnor JM, Oliver JL, Waugh CM, Myer GD, Moore IS, Lloyd RS. The influence of growth and maturation on stretch-shortening cycle function in youth. Sports Med. 2018;48(1):57-71; doi: 10.1007/s40279-017-0785-0.

17. Baroni BM, Ruas CV, Ribeiro-Alvares JB, Pinto RS. Hamstring-to-quadriceps torque ratios of professional male soccer players: a systematic review. J Strength Cond Res. 2020;34(1):281-293; doi: 10.1519/JSC.00000000 00002609.

18. Carvalho HM, Coelho-e-Silva M, Valente-dos-Santos J, Gonçalves RS, Philippaerts R, Malina R. Scaling lowerlimb isokinetic strength for biological maturation and body size in adolescent basketball players. Eur J Appl Physiol. 2012;112(8):2881-2889; doi: 10.1007/s00421011-2259-7.

19. Loturco I, Pereira LA, Kobal R, Kitamura K, Cal Abad CC, Marques G, et al. Validity and usability of a new system for measuring and monitoring variations in vertical jump performance. J Strength Cond Res. 2017; 31(9):2579-2585; doi:10.1519/JSC.0000000000002086.

20. McHugh MP, Clifford T, Abbott W, Kwiecien SY, Kremenic IJ, DeVita JJ, et al. Countermovement jump recovery in professional soccer players using an inertial sensor. Int J Sports Physiol Perform. 2019;14(1):9-15; doi: 10.1123/ijspp.2018-0131.

21. Toonstra J, Mattacola CG. Test-retest reliability and validity of isometric knee-flexion and -extension measurement using 3 methods of assessing muscle strength. J Sport Rehabil. 2013;22(1); doi: 10.1123/jsr.2013.tr7.

22. Reilly T, Bangsbo J, Franks A. Anthropometric and physiological predispositions for elite soccer. J Sports Sci. 2000;18(9):669-683; doi: 10.1080/02640410050 120050 .

23. Rebelo A, Brito J, Maia J, Coelho-e-Silva MJ, Figueiredo AJ, Bangsbo J, et al. Anthropometric characteristics, physical fitness and technical performance of under-19 soccer players by competitive level and field position. Int J Sports Med. 2013;34(4):312-317; doi: 10.1055/s-0032-1323729.

24. Ferioli D, Bosio A, La Torre A, Carlomagno D, Connolly DR, Rampinini E. Different training loads partially influence physiological responses to the preparation period in basketball. J Strength Cond Res. 2018;32(3): 790-797; doi: 10.1519/JSC.0000000000001823.

25. Loturco I, Jeffreys I, Kobal R, Cal Abad CC, RamirezCampillo R, Zanetti V, et al. Acceleration and speed performance of Brazilian elite soccer players of different age-categories. J Hum Kinet. 2018;64:205-218; doi: 10.1515/hukin-2017-0195.
26. Hopkins WG, Marshall SW, Batterham AM, Hanin J. Progressive statistics for studies in sports medicine and exercise science. Med Sci Sports Exerc. 2009;41(1):313; doi: 10.1249/MSS.0b013e31818cb278.

27. Loturco I, Kobal R, Gil S, Pivetti B, Kitamura K, Pereira LA, et al. Differences in loaded and unloaded vertical jumping ability and sprinting performance between Brazilian elite under-20 and senior soccer players. Am J Sport Sci. 2014;2(6-1):8-13; doi: 10.11648/j.ajss.s. 2014020601.12.

28. Mandic R, Jakovljevic S, Jaric S. Effects of countermovement depth on kinematic and kinetic patterns of maximum vertical jumps. J Electromyogr Kinesiol. 2015;25(2):265-272; doi: 10.1016/j.jelekin.2014.11.001.

29. Glaister M. Multiple sprint work: physiological responses, mechanisms of fatigue and the influence of aerobic fitness. Sports Med. 2005;35(9):757-777; doi: 10.2165/ 00007256-200535090-00003.

30. Meerits T, Bacchieri S, Pääsuke M, Ereline J, Cicchella A, Gapeyeva H. Acute effect of static and dynamic stretching on tone and elasticity of hamstring muscles and on vertical jump performance in track-and-field athletes. Acta Kinesiol Univ Tartu. 2014;20:48-59; doi: 10.12697/akut.2014.20.05.

31. Oliveira ML, Ferreira IC, Ferreira KR, Silveira-Nunes G, Barbosa MA, Barbosa AC. Validity of an inexpensive hanging scale during isometric shoulder movements. J Sport Rehabil. 2020;29(8):1218-1221; doi: 10.1123/ jsr.2019-0255.

32. Deprez D, Valente-Dos-Santos J, Coelho-e-Silva MJ, Lenoir M, Philippaerts R, Vaeyens R. Multilevel development models of explosive leg power in high-level soccer players. Med Sci Sports Exerc. 2015;47(7):1408-1415; doi: 10.1249/MSS.0000000000000541.

33. Lehance C, Binet J, Bury T, Croisier JL. Muscular strength, functional performances and injury risk in professional and junior elite soccer players. Scand J Med Sci Sports. 2009;19(2):243-251; doi: 10.1111/j. 1600-0838.2008.00780.x.

34. Mujika I, Santisteban J, Impellizzeri FM, Castagna C. Fitness determinants of success in men's and women's football. J Sports Sci. 2009;27(2):107-114; doi: 10. 1080/02640410802428071.

35. Harley JA, Hind K, O’Hara JP. Three-compartment body composition changes in elite rugby league players during a super league season, measured by dual-energy X-ray absorptiometry. J Strength Cond Res. 2011;25(4): 1024-1029; doi: 10.1519/JSC.0b013e3181cc21fb.

36. Deprez D, Vaeyens R, Coutts AJ, Lenoir M, Philippaerts R. Relative age effect and Yo-Yo IR1 in youth soccer. Int J Sports Med. 2012;33(12):987-993; doi: 10.1055/s-0032-1311654.

37. McGuigan MR, Doyle TLA, Newton M, Edwards DJ, Nimphius S, Newton RU. Eccentric utilization ratio: effect of sport and phase of training. J Strength Cond Res. 2006;20(4):992-995; doi: 10.1519/R-19165.1. 
38. Impellizzeri FM, Rampinini E, Castagna C, Martino F, Fiorini S, Wisloff U. Effect of plyometric training on sand versus grass on muscle soreness and jumping and sprinting ability in soccer players. Br J Sports Med. 2008;42(1):42-46; doi: 10.1136/bjsm.2007.038497.

39. Ramirez-Campillo R, Sanchez-Sanchez J, Romero-Moraleda B, Yanci J, García-Hermoso A, Clemente FM. Effects of plyometric jump training in female soccer player's vertical jump height: a systematic review with meta-analysis. J Sports Sci. 2020;38(13):1475-1487; doi: 10.1080/02640414.2020.1745503.

40. Duarte JP, Valente-Dos-Santos J, Coelho-e-Silva MJ, Malina RM, Deprez D, Philippaerts R, et al. Developmental changes in isometric strength: longitudinal study in adolescent soccer players. Int J Sports Med. 2018;39(9):688-695; doi: 10.1055/s-0044-100389.

41. Loturco I, Pereira LA, Freitas TT, Alcaraz PE, Zanetti V, Bishop C, et al. Maximum acceleration performance of professional soccer players in linear sprints: is there a direct connection with change-of-direction ability? PLoS One. 2019;14(5):e0216806; doi: 10.1371/journal.pone.0216806.

42. Cometti G, Maffiuletti NA, Pousson M, Chatard JC, Maffulli N. Isokinetic strength and anaerobic power of elite, subelite and amateur French soccer players. Int J Sports Med. 2001;22(1):45-51; doi: 10.1055/s-200111331.

43. Zebis MK, Andersen LL, Ellingsgaard H, Aagaard P. Rapid hamstring/quadriceps force capacity in male vs. female elite soccer players. J Strength Cond Res. 2011;25(7):1989-1993; doi: 10.1519/JSC.0b013e3181 e501a6.

44. Greco CC, Da Silva WL, Camarda SRA, Denadai BS. Rapid hamstrings/quadriceps strength capacity in professional soccer players with different conventional isokinetic muscle strength ratios. J Sport Sci Med. 2012; 11(3):418-422.

45. Peek K, Gatherer D, Bennett KJM, Fransen J, Watsford M. Muscle strength characteristics of the hamstrings and quadriceps in players from a high-level youth football (soccer) academy. Res Sports Med. 2018; 26(3):276-288; doi:10.1080/15438627.2018.1447475.

46. Bogdanis GC, Kalapotharakos VI. Knee extension strength and hamstrings-to-quadriceps imbalances in elite soccer players. Int J Sports Med. 2015;37(2):119124; doi: 10.1055/s-0035-1559686.

47. Gür H, Akova B, Pündük Z, Küçükoglu S. Effects of age on the reciprocal peak torque ratios during knee muscle contractions in elite soccer players. Scand J Med Sci Sports. 1999;9(2):81-87; doi: 10.1111/j.1600-0838.1999. tb00213.x.

48. Lee JWY, Mok K-M, Chan HCK, Yung PSH, Chan K-M. Eccentric hamstring strength deficit and poor hamstring-to-quadriceps ratio are risk factors for hamstring strain injury in football: a prospective study of 146 professional players. J Sci Med Sport. 2018;21(8):789793; doi: 10.1016/j.jsams.2017.11.017. 